\title{
Optimization of the Cathode Arc Plasma Deposition Processing Parameters of ZnO Film Using the Grey-Relational Taguchi Method
}

\author{
Shuo-Fu Hsu, ${ }^{1}$ Jyh-Horng Chou, ${ }^{1}$ Chun-Hsiung Fang, ${ }^{1}$ and Min-Hang Weng ${ }^{2}$ \\ ${ }^{1}$ Department of Electrical Engineering, National Kaohsiung University of Applied Sciences, Kaohsiung 807, Taiwan \\ ${ }^{2}$ Medical Devices and Opto-Electronics Equipment Department, Metal Industry Research and Development Center, \\ Kaohsiung 821, Taiwan
}

Correspondence should be addressed to Min-Hang Weng; hcwweng@gmail.com

Received 22 November 2013; Accepted 14 April 2014; Published 8 May 2014

Academic Editor: Chien-Hung Yeh

Copyright @ 2014 Shuo-Fu Hsu et al. This is an open access article distributed under the Creative Commons Attribution License, which permits unrestricted use, distribution, and reproduction in any medium, provided the original work is properly cited.

\begin{abstract}
We deposited undoped $\mathrm{ZnO}$ films on the glass substrate at a low temperature $\left(<70^{\circ} \mathrm{C}\right)$ using cathode arc plasma deposition (CAPD) and the grey-relational Taguchi method was used to determine the processing parameters of $\mathrm{ZnO}$ thin films. The Taguchi method with an L9 orthogonal array, signal-to-noise $(S / N)$ ratio, and analysis of variance (ANOVA) is employed to investigate the performances in the deposition operations. The effect and optimization of deposition parameters, comprising the $\mathrm{Ar}$ : $\mathrm{O}_{2}$ gas flow ratio of $1: 6,1: 8$, and $1: 10$, the arc current of $50 \mathrm{~A}, 60 \mathrm{~A}$, and $70 \mathrm{~A}$, and the deposition time of $5 \mathrm{~min}, 10 \mathrm{~min}$, and $15 \mathrm{~min}$, on the electrical resistivity and optical transmittance of the $\mathrm{ZnO}$ films are studied. The results indicate that, by using the grey-relational Taguchi method, the optical transmittance of $\mathrm{ZnO}$ thin films increases from $88.17 \%$ to $88.82 \%$ and the electrical resistivity decreases from $5.12 \times 10^{-3} \Omega$-cm to $4.38 \times 10^{-3} \Omega$-cm, respectively.
\end{abstract}

\section{Introduction}

Zinc oxide $(\mathrm{ZnO})$ has gained a great interest in research due to wide and direct band gap $(3.3 \mathrm{eV})$ and excellent optoelectronic properties, which are desirable for optoelectronic devices such as photodetectors, solar cells, light emission diodes, gas sensor, varistors, and ultraviolet laser diodes [1]. And $\mathrm{ZnO}$ thin films also obtain a processing advantage of thermal stability, which does not suffer from dislocation degradation during operation. Moreover, pure or doped $\mathrm{ZnO}$ thin films have been considered as good candidates to be transparent conductive oxide (TCO) materials because of their good optical transmittance, low electrical resistivity, and low-cost fabrication [2-9].

Highly transparent and conducting $\mathrm{ZnO}$ films have been deposited by several different methods, including chemical vapor deposition (CVD) [2], thermal oxidation [3], radio frequency $(\mathrm{RF})$ magnetron sputtering [4], pulsed laser deposition [5], electron beam evaporation [6], spray pyrolysis [7], electrodeposition [8], and the cathodic arc plasma deposition
(CAPD) [9-14]. Most of the mentioned deposition methods need a high substrate temperature or in situ annealing process $\left(>300^{\circ} \mathrm{C}\right)$ to obtain desired optical and/or electrical properties. However, in order to avoid reactive and elemental diffusion of different layers and to protect substrates having thermal stress, low temperature deposition is preferred in some processes. It is, thus, a challenge to deposit high quality $\mathrm{ZnO}$ thin films with desired optical and/or electrical properties at a low temperature. Among various deposition methods, CAPD technique has many advantages, including high deposition rate, convenient in situ doping using an overlying plasma, and the readily adjustable deposition parameters, such as substrate temperature, arc current, gas flow rate, and deposition time [9-12].

The Taguchi method [15-17] uses many ideas from the statistical experimental design for evaluating and implementing improvements in products, processes, and equipment. The Taguchi method is used to study a large number of design variables with a small number of experiments. The better level combinations of design variables are decided by the 


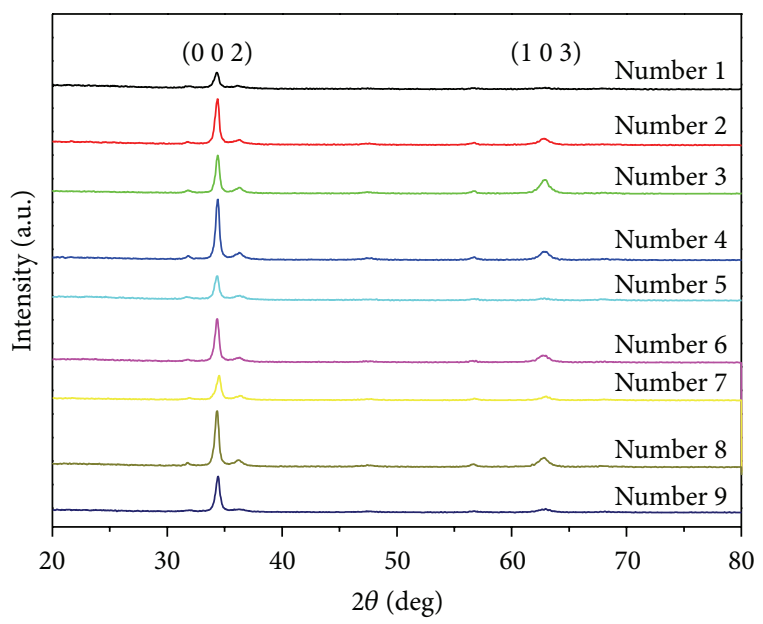

FIgURE 1: The XRD patterns of the of the $\mathrm{ZnO}$ films on glass substrates for the L9 orthogonal array from experiments number $1 \sim 9$.

orthogonal arrays and signal-to-noise $(S / N)$ ratios. In 1982, grey analysis was first proposed by Deng to fulfill the crucial mathematical criteria for dealing with poor, incomplete, and uncertain systems [18]. Grey analysis can effectively recommend a method of optimizing the complicated interrelationships among multiple performance characteristics [19]. In grey system theory, the grey-relational analysis is a measurement method to analyze the relationship between sequences using less data and multifactor, which is considered more helpful to the statistical regression analysis. There are few papers concerning the examination on properties of $\mathrm{ZnO}$ thin films by using grey-relational Taguchi method [20-22]. However, there is no related research concerning grey-relational Taguchi method to design the processing parameters for depositing $\mathrm{ZnO}$ thin films by using CAPD.

In this paper, we deposited undoped $\mathrm{ZnO}$ thin films on the glass substrate at a low temperature $\left(<70^{\circ} \mathrm{C}\right)$ using cathode arc plasma deposition, and the grey-relational Taguchi method was used to determine the optimal processing parameters including the gas flow ratio, the arc current, and the deposition time. By using the grey-relational Taguchi method, the experimental results confirm that the optical transmittance of $\mathrm{ZnO}$ thin films increases from $88.17 \%$ to $88.82 \%$ and the electrical resistivity decreases from $5.12 \times$ $10^{-3} \Omega$-cm to $4.38 \times 10^{-3} \Omega$-cm, respectively. Namely, the Grey analysis is actually an effectively optimizing method of the multiprocessing parameters for depositing $\mathrm{ZnO}$ thin films by using CAPD.

\section{Experimental Method and Optimization Approach}

$\mathrm{ZnO}$ films were deposited onto the glass substrate in a CAPD system. Metallic $\mathrm{Zn}$ with a diameter of $100 \mathrm{~mm}$ and a purity of $99.99 \%$ as a cathode target was held in an alumina ceramic tube and $\mathrm{O}_{2}$ gas with a high purity of $99.99 \%$ was used as the reactant gas. Before deposition, glass substrates were
TABLE 1: Deposition parameters of $\mathrm{ZnO}$ films factors and levels using cathode arc plasma deposition (CAPD).

\begin{tabular}{|c|c|c|c|}
\hline Substrate & \multicolumn{3}{|c|}{ glass } \\
\hline Target & \multicolumn{3}{|c|}{$\begin{array}{l}\text { Zinc: } 99.99 \% \text { purity } \\
100 \mathrm{~mm} \text { diameter }\end{array}$} \\
\hline Base pressure & \multicolumn{3}{|c|}{$7 \times 10^{-4}$ torr } \\
\hline Substrate-to-target distance & \multicolumn{3}{|c|}{$21 \mathrm{~cm}$} \\
\hline Substrate rotation & \multicolumn{3}{|c|}{ 2 r.p.m } \\
\hline \multirow[t]{3}{*}{ Substrate temperature } & \multicolumn{3}{|c|}{ Room temperature } \\
\hline & \multicolumn{3}{|c|}{ Level } \\
\hline & 1 & 2 & 3 \\
\hline A: gas flow ratio $\left(\mathrm{Ar}: \mathrm{O}_{2}\right)$ & $1: 6$ & $1: 10$ & $1: 8$ \\
\hline$B: \operatorname{arc}$ current $(\mathrm{A})$ & 50 & 60 & 70 \\
\hline C: deposition time (min) & 5 & 10 & 15 \\
\hline
\end{tabular}

washed by alcohol and then ultrasonically cleaned in alcohol for $10 \mathrm{~min}$. In the depositions of $\mathrm{ZnO}$ films, base pressure was kept at $3 \times 10^{-4}$ torr. Substrate rotation of 2 r.p.m. and substrate-anode electrode distance of approximately $21 \mathrm{~cm}$ remained constant during the deposition work. Without extra heating, the depositions of $\mathrm{ZnO}$ films were performed at room temperature.

The $\mathrm{ZnO}$ films with different thicknesses were confirmed by the measurement of Alpha-Step ( $\alpha$-step, Kosaka Laboratory Ltd. ET-4000). X-ray diffraction system (XRD, BRUKER D8 ADVANCE) equipped with $\mathrm{CuK} \alpha$ radiation of average wavelength 1.5406 Á was used to specify the existent phases and the orientation of $\mathrm{ZnO}$ thin films. X-ray patterns were taken with $2 \theta$ between $20^{\circ}$ and $60^{\circ}$ and a scan speed of $4.5^{\circ} / \mathrm{min}$. UV-VIS spectrometer (Thermo Evolution 300) was used to measure the optical properties of $\mathrm{ZnO}$ films in the wavelength range of $300-800 \mathrm{~nm}$. The standard fourpoint probe method was used for room-temperature sheet resistance of the films.

The L9 orthogonal array was selected in this paper. There are three factors in the $\mathrm{ZnO}$ deposition processing, which are the $\mathrm{Ar}: \mathrm{O}_{2}$ gas flow ratio of $1: 6,1: 8$, and $1: 10$, the arc current of $50 \mathrm{~A}, 60 \mathrm{~A}$, and $70 \mathrm{~A}$, and the deposition time of 5, 10, and $15 \mathrm{~min}$. Each experiment was repeated two times in this study. Table 1 shows factor and level setting in $\mathrm{ZnO}$ deposition parameters.

2.1. Analysis of the $S / N$ Ratio. Taguchi method was used to execute the experiment, employing a generic signal-to-noise $(S / N)$ ratio to quantify the present variation. Depending on the particular type of characteristics, $S / N$ ratios may be defined as "the lower the better" or "the higher the better." The $S / N$ ratios were calculated using the following equations [12].

The lower the better is as follows:

$$
\frac{S}{N}=-10 \times \log \left(\frac{1}{n} \sum_{i=1}^{n} y_{i}^{2}\right)
$$




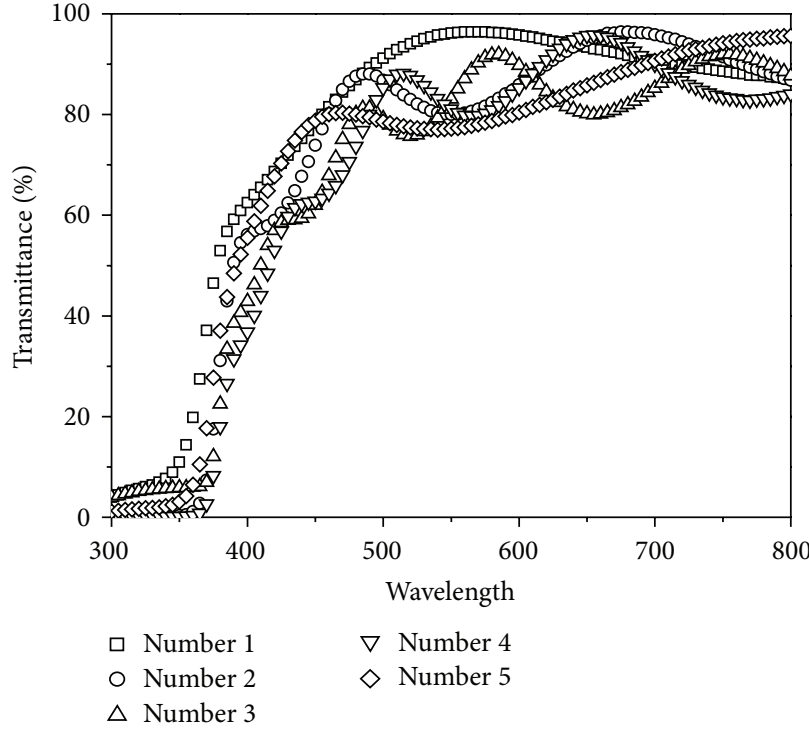

(a)

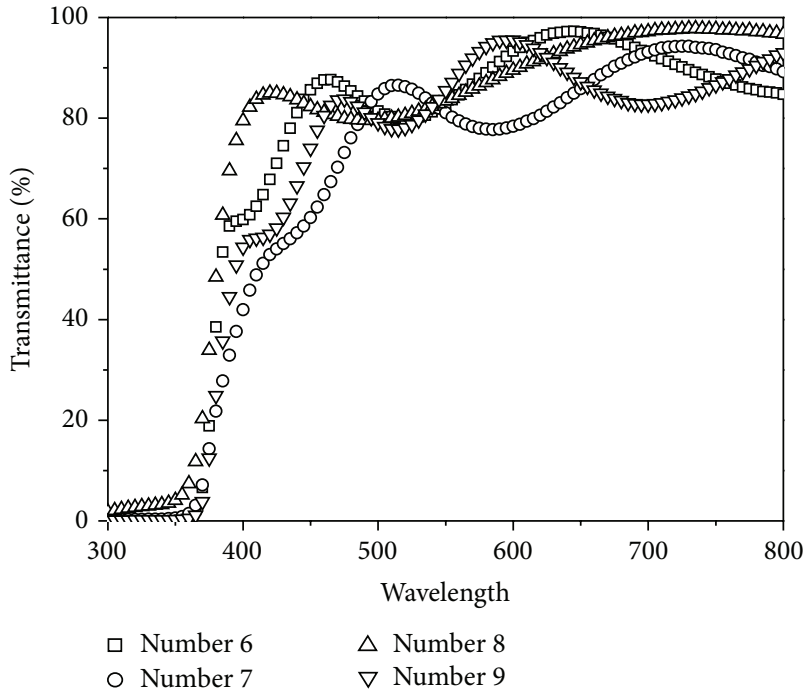

(b)

Figure 2: The optical transmittance of the deposited $\mathrm{ZnO}$ thin films as a function of wavelength; (a) experiments number 1 5 and (b) experiments number 6 9.

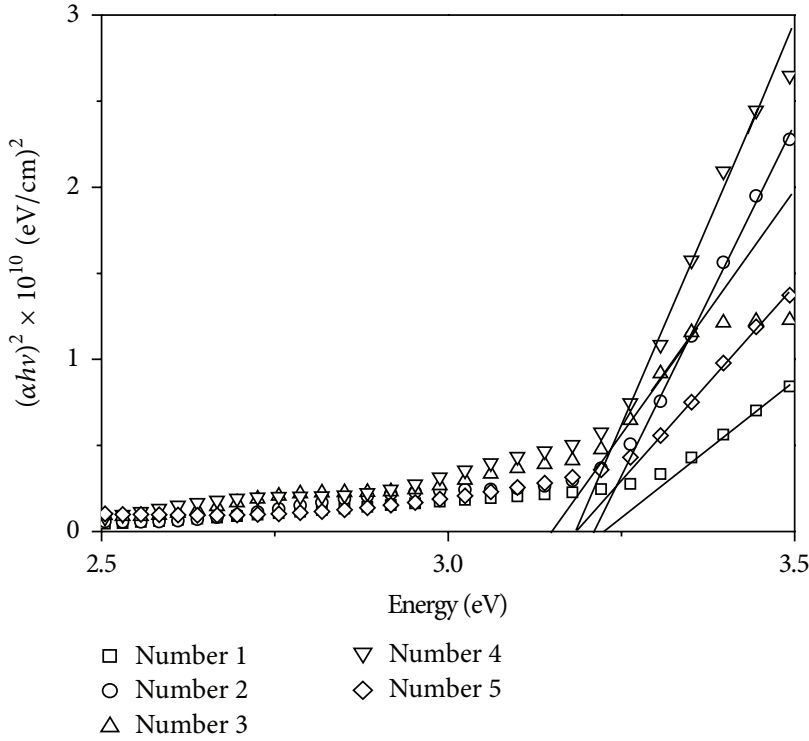

(a)

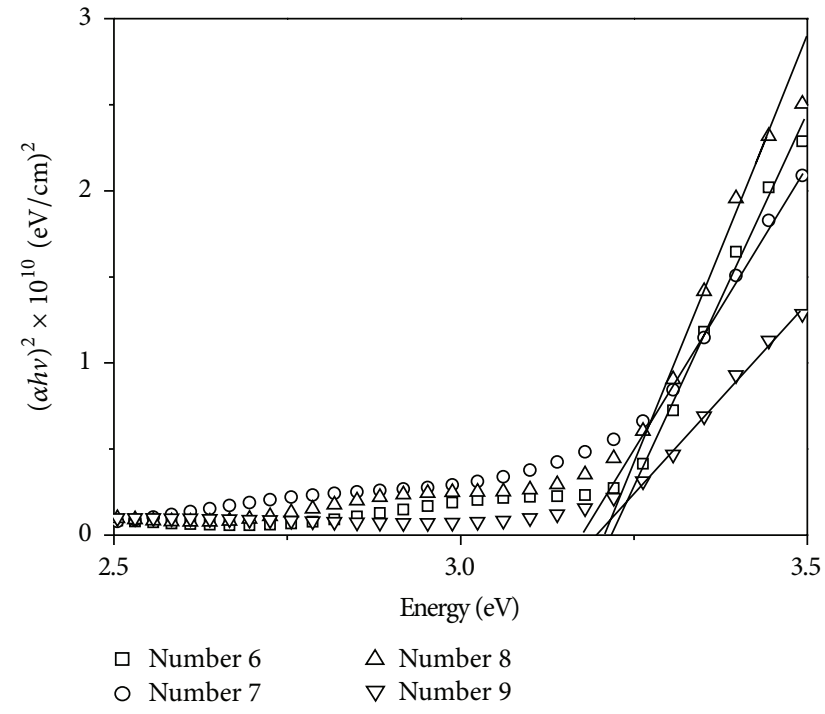

(b)

FIgURE 3: The optical energy gaps of the $\mathrm{ZnO}$ thin films; (a) experiments number 1 5 and (b) experiments number 6 9.

the lower the better is as follows:

$$
\frac{S}{N}=-10 \times \log \left(\frac{1}{n} \sum_{i=1}^{n} \frac{1}{y_{i}^{2}}\right),
$$

where $n$ is the number of experiment and $y$ is the experimental data; the $S / N$ ratio is expressed on a decibel scale (dB). The mean $S / N$ ratio for each level of the parameters is summarized and obtained as the $S / N$ response graph used to analyze the $S / N$ ratio of each experimental parameter. Then, we can obtain the best level combination of deposition parameters.

2.2. Analysis of Variance (ANOVA). The purpose of the analysis of variance (ANOVA) is to investigate which design parameters significantly affect the quality characteristic. This is accomplished by separating the total variability of the $S / N$ ratios, which is measured by the sum of the squared 
TABLE 2: Grain size of $\mathrm{ZnO}$ thin films for the L9 orthogonal array from experiments 1 9.

\begin{tabular}{lllll}
\hline $\begin{array}{l}\text { Experiment } \\
\text { number }\end{array}$ & \multicolumn{3}{c}{ Control factors } & Grain size (nm) \\
\hline 1 & 1 & $B$ & $C$ & \\
2 & 2 & 2 & 2 & 21.08 \\
3 & 3 & 3 & 3 & 21.08 \\
4 & 1 & 2 & 3 & 21.62 \\
5 & 2 & 3 & 1 & 19.61 \\
6 & 3 & 1 & 2 & 18.74 \\
7 & 1 & 3 & 2 & 19.16 \\
8 & 2 & 1 & 3 & 20.57 \\
9 & 3 & 2 & 1 & 21.62 \\
\hline
\end{tabular}

deviations from the total mean $S / N$ ratio. The analysis of variance and the contribution of each design parameter are obtained by following equation:

$$
\begin{gathered}
S_{m}=\frac{\left(\sum \eta_{i}\right)^{2}}{N}, \quad S_{T}=\sum \eta_{i}^{2}-S_{m}, \\
S_{A}=\frac{\sum \eta_{A i}^{2}}{n}, \\
V_{A}=\frac{S_{A}}{f_{A}}, \\
C_{A}=\frac{S_{A}}{S_{T}} \times 100 \%,
\end{gathered}
$$

where $S_{m}$ is the sum of squares due to the means, $S_{T}$ is the sum of squares due to the total variation, $S_{A}$ is the sum of squares due to parameter $A, f_{A}$ is the degree of freedom of parameter $A, V_{A}$ is the variance of parameter $A$, and $C_{A}$ is the contribution of each design parameter.

2.3. Grey-Relational Analysis. Grey-relational analysis can be used to effectively solve complicated interrelationships among multiple performance characteristics. The greyrelational coefficient is [18]

$$
\begin{aligned}
r\left(x_{0}(k), x_{i}(k)\right) \\
=\left(\min _{i} \min _{k}\left|x_{0}(k)-x_{i}(k)\right|+\zeta \max _{i} \max _{k}\left|x_{0}(k)-x_{i}(k)\right|\right) \\
\quad \times\left(\left|x_{0}(k)-x_{i}(k)\right|+\zeta \max _{i} \max _{k}\left|x_{0}(k)-x_{i}(k)\right|\right)^{-1} .
\end{aligned}
$$

Grey-relational analysis can be used to effectively solve complicated interrelationships among multiple performances, where $x_{i}(k)$ is the normalized value of the $k$ th performance characteristic in the $i$ th experiment and $\zeta$ is the distinguishing coefficient, $\zeta \in[0,1]$. The value of $\zeta$ can be adjusted according to the practical system requirement. Transmittance and resistivity are equally weighted in this paper; therefore, $\zeta$ is 0.5 .

The grey-relational grade is a weighting-sum of the grayrelational coefficient. It is defined as follows [19]:

$$
r\left(x_{0}, x_{i}\right)=\frac{1}{n} \sum_{k=1}^{n} r\left(r_{0}(k), x_{i}(k)\right),
$$

where $n$ is the number of performance characteristic. The gray-relational grade shows the correlation between the reference sequence and the comparability sequence which is compared. The evaluated grey-relational grade fluctuates from 0 to 1 and equals one, if these two sequences are identically coincident.

\section{Results and Discussions}

Figure 1 shows the $\mathrm{XRD}$ patterns of the of the $\mathrm{ZnO}$ films on glass substrates for the L9 orthogonal array from experiments number 1 9. For all as-grown films, $\left(\begin{array}{lll}0 & 0 & 2\end{array}\right)$ diffraction peaks at around $34.2^{\circ}$ and $\left(\begin{array}{lll}1 & 0 & 3\end{array}\right)$ diffraction peaks at around $62.4^{\circ}$ appear in the diffractogram, indicating that the films reveal a polycrystalline hexagonal wurtzite crystal structure $(a=$ $3.249, c=5.206 \AA ̊$ ). Moreover, except for experiment number 3 , all of $\mathrm{ZnO}$ thin films present that the diffraction intensity of the $\left(\begin{array}{lll}0 & 0 & 2\end{array}\right)$ direction is much stronger than that of the $(1$ 03 ) direction, indicating that the structure of the $\mathrm{ZnO}$ thin films is preponderantly consist of columnar grains standing perpendicular to the substrate. The average grain size $(D)$ of the $\mathrm{ZnO}$ films is determined by applying the Scherrer equation to the full width at half maximum (FWHM) of the $\left(\begin{array}{lll}0 & 0 & 2\end{array}\right)$ peaks, as given by [23]

$$
D=\frac{0.9 \lambda}{\omega \cos \theta}
$$

where $\omega$ is the calibrated FWHM of the selected diffraction line in radians, $\theta$ is the Bragg angle, and $\lambda$ is the $\mathrm{X}$ ray wavelength $(0.15406 \mathrm{~nm})$. Table 2 shows grain size of deposited $\mathrm{ZnO}$ thin films for the L9 orthogonal array from experiments number $1 \sim 9$.

Figure 2 shows the optical transmittance of the deposited $\mathrm{ZnO}$ thin films as a function of wavelength. From the measured optical transmittance of the deposited $\mathrm{ZnO}$ thin films, the average transmittance can be obtained [24]. Moreover, the variation of the absorption coefficient $\alpha$ with the photon energy $h v$ can be given as [25]

$$
(\alpha h v)^{2}=B(h v-E g),
$$

where $\alpha$ was estimated from the transmittance data and $B$ is a constant depending on the materials' properties. By plotting $(\alpha h \nu)^{2}$ as a function of $h \nu$ and extrapolating to $\alpha=0$ from the linear region of "Tauc" plots, the optical energy gaps of the $\mathrm{ZnO}$ thin films can be obtained. As shown in Figure 3, the optical energy gaps of the $\mathrm{ZnO}$ thin films are in the range of $3.15 \sim 3.2 \mathrm{eV}$, indicating that undoped $\mathrm{ZnO}$ films were successfully deposited on the glass substrate at a low 
TABLE 3: Experimental results for the transmittance and resistivity of the deposited ZnO films on glass substrate.

\begin{tabular}{lccccccccc}
\hline $\begin{array}{l}\text { Experiment } \\
\text { number }\end{array}$ & \multicolumn{3}{c}{ Control factors } & \multicolumn{3}{c}{ Transmittance (\%) } & \multicolumn{3}{c}{ Resistivity $\left(10^{-3} \Omega\right.$-cm) } \\
\hline 1 & $A$ & $B$ & $C$ & $Y 1$ & $Y 2$ & Mean value & $Y 1$ & Y2 & Mean value \\
2 & 1 & 1 & 1 & 87.57 & 86.73 & 87.15 & 5.56 & 4.59 & 5.51 \\
3 & 2 & 2 & 2 & 83.17 & 82.47 & 82.82 & 6.19 & 5.71 & 5.95 \\
4 & 3 & 3 & 3 & 77.71 & 77.43 & 77.57 & 2.99 & 2.79 & 2.89 \\
5 & 1 & 2 & 3 & 78.14 & 77.66 & 77.90 & 6.75 & 5.97 & 6.36 \\
6 & 2 & 3 & 1 & 81.25 & 79.61 & 80.43 & 7.25 & 5.99 & 6.62 \\
7 & 3 & 1 & 2 & 84.98 & 84.82 & 84.90 & 6.13 & 5.93 & 6.03 \\
8 & 1 & 3 & 2 & 77.96 & 77.34 & 77.65 & 5.46 & 5.23 & 5.35 \\
9 & 2 & 1 & 3 & 80.39 & 80.17 & 80.28 & 4.32 & 4.28 & 4.30 \\
\hline
\end{tabular}

TABLE 4: Grey-relational grade and $S / N$ ratio.

\begin{tabular}{lccccc}
\hline $\begin{array}{l}\text { Experiment } \\
\text { number }\end{array}$ & \multicolumn{3}{c}{ Control factors } & $\begin{array}{c}\text { Grey-relational } \\
\text { grade }\end{array}$ & $\begin{array}{c}S / N \\
(\mathrm{~dB})\end{array}$ \\
\hline 1 & $\mathrm{~A}$ & $\mathrm{~B}$ & $\mathrm{C}$ & 0.6589 & -3.62 \\
2 & 1 & 1 & 1 & 0.4440 & -7.05 \\
3 & 2 & 2 & 2 & 0.6667 & -3.52 \\
4 & 3 & 3 & 3 & 0.3452 & -9.24 \\
5 & 1 & 2 & 3 & 0.3720 & -8.59 \\
6 & 2 & 3 & 1 & 0.5083 & -5.88 \\
7 & 3 & 1 & 2 & 0.3832 & -8.33 \\
8 & 1 & 3 & 2 & 0.4876 & -6.24 \\
9 & 2 & 1 & 3 & 0.7137 & -2.93 \\
\hline
\end{tabular}

TABLE 5: $S / N$ response for grey-relational grade.

\begin{tabular}{lcccc}
\hline \multirow{2}{*}{ Parameters } & \multicolumn{3}{c}{ Mean $S / N$ ratio $(\mathrm{dB})$} & Optimal \\
& Level 1 & Level 2 & Level 3 & parameters \\
\hline $\begin{array}{l}\text { A: gas flow ratio } \\
\left(\text { Ar: } \mathrm{O}_{2}\right)\end{array}$ & -7.06 & -7.29 & -4.11 & $A 3$ \\
$B$ : arc current & -5.25 & -6.41 & -6.81 & $B 1$ \\
$C$ : deposition time & -5.05 & -7.09 & -6.33 & $C 1$ \\
\hline
\end{tabular}

TABLE 6: Results of confirmation test for multiple performance characteristics of $\mathrm{ZnO}$ thin films.

\begin{tabular}{lc}
\hline Resistivity & Transmittance \\
& \multicolumn{1}{c}{ Experiment number $9(A 3 B 2 C 1)$} \\
\hline $5.12 \times 10^{-3} \Omega$-cm & $88.17 \%$ \\
\hline Grey-relational prediction design $(A 3 B 1 C 1)$ \\
$4.38 \times 10^{-3} \Omega$-cm & $88.82 \%$ \\
\hline
\end{tabular}

temperature $\left(<70^{\circ} \mathrm{C}\right)$ by using cathodic arc plasma deposition in this experiment.

Table 3 shows the experimental results for the transmittance and resistivity of the deposited $\mathrm{ZnO}$ thin films on glass using CAPD. Table 4 shows the grey-relational grade for each experiment by using (4) and (5) and its $S / N$ ratio by using (1). The results indicate that number 9 experiment has the highest grey-relational grade. The larger the grey-relational grade is, the better the multiple performance characteristics will be. Table 5 shows $S / N$ response for grey-relational grade. As shown, the optimal parameters are the gas flow ratio $\left(\mathrm{Ar}: \mathrm{O}_{2}\right)$ of 1:10, arc current of $50 \mathrm{~A}$, and deposition time of $5 \mathrm{~min}$. Hence, the optimal parameter level was selected to accomplish the proof experiment. Experiment number 9 has the best Grey-relational grade, indicating that it has superior multiple performance characteristics compared with another eight experiments. Table 6 shows the result of comparison between the grey-relational prediction design $(A 3 B 1 C 1)$ and orthogonal array experiment number $9(A 3 B 2 C 1)$. The result indicates that the resistivity decreases from $5.12 \times 10^{-3} \Omega$ $\mathrm{cm}$ to $4.38 \times 10^{-3} \Omega$-cm and transmittance increases from $88.17 \%$ to $88.82 \%$. Table 7 shows the ANOVA results of greyrelational grade for $\mathrm{ZnO}$ thin films. For this study, the gas flow rate is the most influential processing parameter. However, the arc current and the deposition time should not be ignored.

\section{Conclusions}

In summary, undoped $\mathrm{ZnO}$ films were successfully deposited on the glass substrate at a low temperature $\left(<70^{\circ} \mathrm{C}\right)$ by using cathodic arc plasma deposition. The grey-relational Taguchi method successfully predicted the optimal processing parameters including the $\mathrm{Ar}: \mathrm{O}_{2}$ gas flow ratio, the arc current and the deposition time for multiple performance, the transmittance, and the resistivity of the $\mathrm{ZnO}$ films. The result of the confirmed experiment $(A 3 B 1 C 1)$ showed that the transmittance increases from $88.17 \%$ to $88.82 \%$ and the resistivity decreases from $5.12 \times 10^{-3} \Omega$-cm to $4.38 \times 10^{-3} \Omega$ $\mathrm{cm}$, indicating that the result of final confirmed experiments could be certainly improved.

\section{Conflict of Interests}

The authors declare that there is no conflict of interests regarding the publication of this paper. 
TABLE 7: ANOVA results of grey-relational grade for $\mathrm{ZnO}$ thin films.

\begin{tabular}{lcccc}
\hline Parameters & Degree of freedom $(F)$ & Sum of square $(S)$ & Variance $(V)$ & Contribution $(\%)$ \\
\hline A: gas flow ratio $\left(\mathrm{Ar}: \mathrm{O}_{2}\right)$ & 2 & 18.92 & 9.46 & 65 \\
$B:$ arc current & 2 & 3.97 & 1.99 & 13 \\
C: deposition time & 2 & 6.38 & 3.19 & 22 \\
\hline Total & & 29.27 & & 100 \\
\hline
\end{tabular}

\section{Acknowledgments}

The authors would like to acknowledge Professor R. Y. Yang for supporting the experimental equipment and to acknowledge the part funding support from the Ministry of Economic Affairs, Taiwan, under Grant 103-EC-17-A-230756.

\section{References}

[1] S. Goldsmith, "Filtered vacuum arc deposition of undoped and doped $\mathrm{ZnO}$ thin films: electrical, optical, and structural properties," Surface and Coatings Technology, vol. 201, no. 7, pp. 3993-3999, 2006.

[2] T. Terasako, M. Yagi, M. Ishizaki, Y. Senda, H. Matsuura, and S. Shirakata, "Growth of zinc oxide films and nanowires by atmospheric-pressure chemical vapor deposition using zinc powder and water as source materials," Surface and Coatings Technology, vol. 201, no. 22-23, pp. 8924-8930, 2007.

[3] G. G. Rusu, A. P. Râmbu, V. E. Buta, M. Dobromir, D. Luca, and M. Rusu, "Structural and optical characterization of Al-doped $\mathrm{ZnO}$ films prepared by thermal oxidation of evaporated $\mathrm{Zn} / \mathrm{Al}$ multilayered films," Materials Chemistry and Physics, vol. 123, no. 1, pp. 314-321, 2010.

[4] J. H. Kim, B. D. Ahn, C. H. Kim, K. A. Jeon, H. S. Kang, and S. Y. Lee, "Heat generation properties of Ga doped $\mathrm{ZnO}$ thin films prepared by rf-magnetron sputtering for transparent heaters," Thin Solid Films, vol. 516, no. 7, pp. 1330-1333, 2008.

[5] B. L. Zhu, X. Z. Zhao, F. H. Su et al., "Low temperature annealing effects on the structure and optical properties of $\mathrm{ZnO}$ films grown by pulsed laser deposition," Vacuum, vol. 84, no. 11, pp. 1280-1286, 2010.

[6] D. R. Sahu, S.-Y. Lin, and J.-L. Huang, "Improved properties of Al-doped $\mathrm{ZnO}$ film by electron beam evaporation technique," Microelectronics Journal, vol. 38, no. 2, pp. 245-250, 2007.

[7] E. Bacaksiz, S. Aksu, S. Yilmaz, M. Parlak, and M. Altunbaş, "Structural, optical and electrical properties of Al-doped $\mathrm{ZnO}$ microrods prepared by spray pyrolysis," Thin Solid Films, vol. 518, no. 15, pp. 4076-4080, 2010.

[8] M. Fahoume, O. Maghfoul, M. Aggour, B. Hartiti, F. Chraïbi, and A. Ennaoui, "Growth and characterization of $\mathrm{ZnO}$ thin films prepared by electrodeposition technique," Solar Energy Materials and Solar Cells, vol. 90, no. 10, pp. 1437-1444, 2006.

[9] X. L. Xu, S. P. Lau, J. S. Chen, Z. Sun, B. K. Tay, and J. W. Chai, "Dependence of electrical and optical properties of $\mathrm{ZnO}$ films on substrate temperature," Materials Science in Semiconductor Processing, vol. 4, no. 6, pp. 617-620, 2001.

[10] Y. G. Wang, S. P. Lau, H. W. Lee et al., "Comprehensive study of $\mathrm{ZnO}$ films prepared by filtered cathodic vacuum arc at room temperature," Journal of Applied Physics, vol. 94, no. 3, pp. 15971604, 2003.
[11] H. W. Lee, S. P. Lau, Y. G. Wang, K. Y. Tse, H. H. Hng, and B. K. Tay, "Structural, electrical and optical properties of Aldoped $\mathrm{ZnO}$ thin films prepared by filtered cathodic vacuum arc technique," Journal of Crystal Growth, vol. 268, no. 3-4, pp. 596$601,2004$.

[12] K. Y. Tse, H. H. Hng, S. P. Lau, Y. G. Wang, and S. F. Yu, “ZnO thin films produced by filtered cathodic vacuum arc technique," Ceramics International, vol. 30, no. 7, pp. 1669-1674, 2004.

[13] E. Çetinörgü, S. Goldsmith, and R. L. Boxman, "The effect of annealing on filtered vacuum arc deposited $\mathrm{ZnO}$ thin films," Surface and Coatings Technology, vol. 201, no. 16-17, pp. 72667272, 2007.

[14] Y. F. Mei, R. K. Y. Fu, G. G. Siu et al., "Fabrication of highly (1000) oriented textured zinc oxide films by metal cathodic arc and oxygen dual plasma deposition and their optical properties," Surface and Coatings Technology, vol. 201, no. 19-20, pp. 8348-8351, 2007.

[15] P. J. Ross, Taguchi Techniques for Quality Engineering, McGrawHill, New York, NY, USA, 1989.

[16] Y. Wu, Taguchi Methods for Robust Design, ASME, New York, NY, USA, 2000.

[17] G. Taguchi, S. Chowdhury, and S. Taguchi, Robust Engineering, McGraw-Hill, New York, NY, USA, 2000.

[18] J. L. Deng, "Introduction to grey system," The Journal of Grey System, vol. 1, no. 1, p. 1, 1989.

[19] J. L. Deng, "Introduction to Grey system theory," The Journal of Grey System, vol. 1, no. 1, pp. 1-24, 1989.

[20] C. Y. Hsu, Y. C. Lin, L. M. Kao, and Y. C. Lin, "Effect of deposition parameters and annealing temperature on the structure and properties of Al-doped $\mathrm{ZnO}$ thin films," Materials Chemistry and Physics, vol. 124, no. 1, pp. 330-335, 2010.

[21] C.-C. Chen, C.-C. Tsao, Y.-C. Lin, and C.-Y. Hsu, "Optimization of the sputtering process parameters of GZO films using the Grey-Taguchi method," Ceramics International, vol. 36, no. 3, pp. 979-988, 2010.

[22] C. Y. Chu, C. H. Huang, L. M. Kao et al., "Structure and properties of GZO thin films grown on $\mathrm{ZnO}$ buffer layers," Superlattices and Microstructures, vol. 49, no. 2, pp. 158-168, 2011.

[23] M.-H. Weng, C.-T. Pan, R.-Y. Yang, and C.-C. Huang, "Structure, optical and electrical properties of $\mathrm{ZnO}$ thin films on the flexible substrate by cathodic vacuum arc technology with different arc currents," Ceramics International, vol. 37, no. 8, pp. 3077-3082, 2011.

[24] H. W. Lee, S. P. Lau, Y. G. Wang, B. K. Tay, and H. H. Hng, "Internal stress and surface morphology of zinc oxide thin films deposited by filtered cathodic vacuum arc technique," Thin Solid Films, vol. 458, no. 1-2, pp. 15-19, 2004.

[25] J. I. Pankove, "Relationships between optical constants," in Optical Processes in Semiconductors, chapter 4, Prentice Hall, Englewood Cliffs, NJ, USA, 1971. 

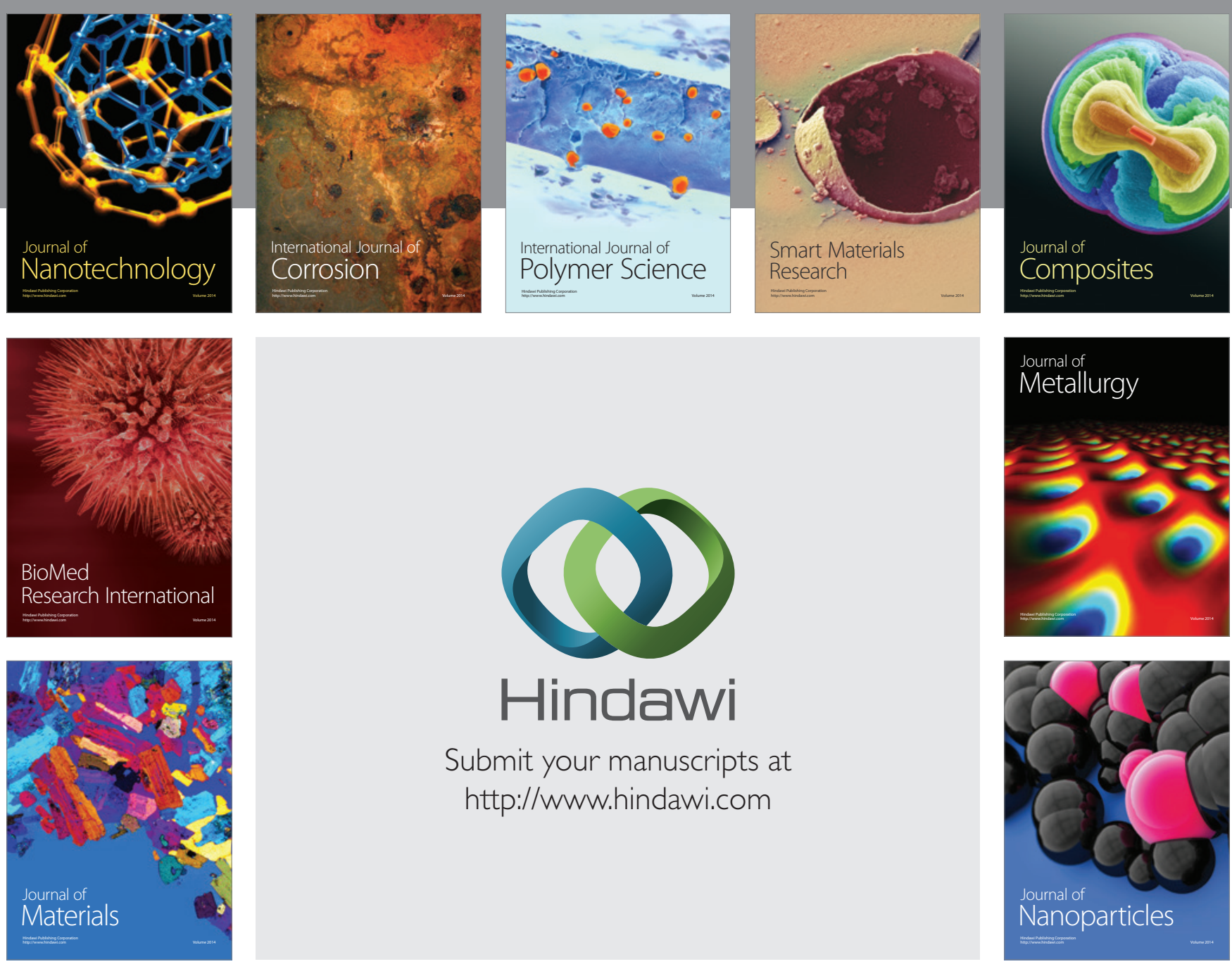

Submit your manuscripts at http://www.hindawi.com
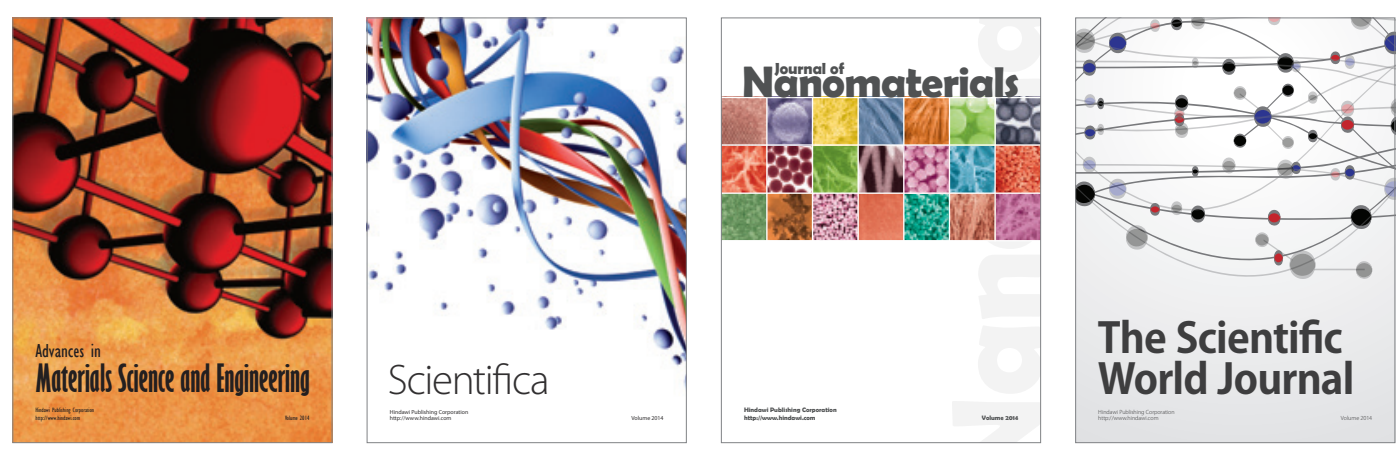

\section{The Scientific World Journal}
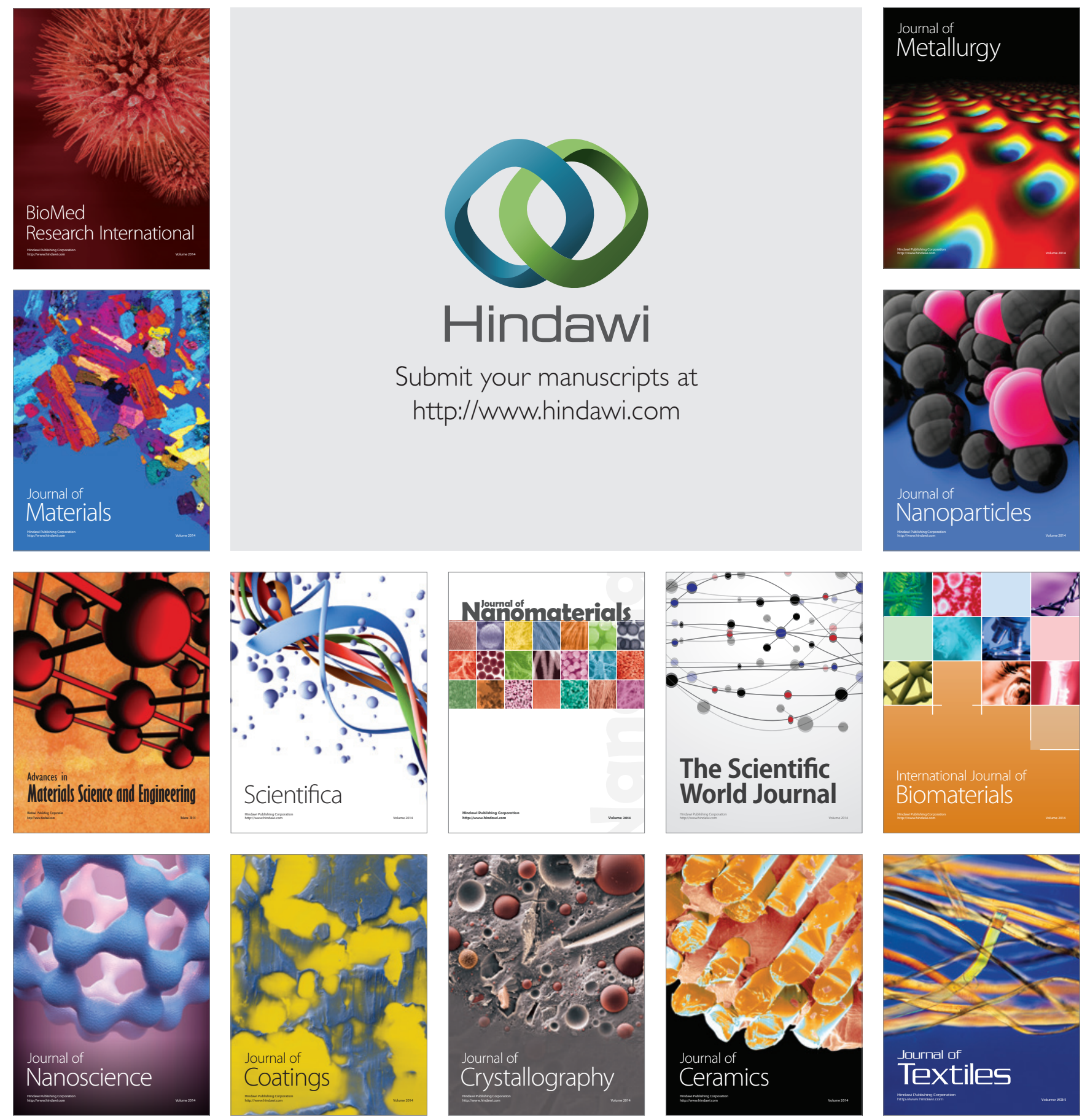